\title{
Nephrotic syndrome in a patient with cystinuria: Questions
}

\author{
Ozlem Yuksel Aksoy ${ }^{1} \cdot$ Nilgun Cakar $^{2}$
}

Received: 26 November 2019 / Accepted: 27 November 2019 /Published online: 13 December 2019

(C) IPNA 2019

Keywords Adolescent $\cdot$ Cystinuria $\cdot$ Kidney stones $\cdot$ Edema

\section{Case presentation}

A 17-year-old female patient, who had been diagnosed with cystinuria and using tiopronin treatment for 6 years, was referred to our pediatric nephrology department with the complaints of swelling on her face and eyelids, abdominal distention, and decreased urine output.

Physical examination was normal except the prominent edema of the eyelids and the pretibial region. The patient was admitted to the nephrology clinic for investigation. Blood pressure, fluid intake, urine output and body weight were closely monitored.

Serum biochemistry revealed urea $21 \mathrm{mg} / \mathrm{dl}$, creatinine $0.64 \mathrm{mg} / \mathrm{dl}$, albumin $1.4 \mathrm{~g} / \mathrm{dl}$, total protein $4.2 \mathrm{~g} / \mathrm{dl}$, cholesterol $142 \mathrm{mg} / \mathrm{dl}$, triglycerides $591 \mathrm{mg} / \mathrm{dl}$, and daily urinary excretion of protein was $226 \mathrm{mg} / \mathrm{m}^{2} / \mathrm{h}$. Serological tests for antinuclear antibody, anti-dsDNA and HBs antigen were negative. Serum C3 and C4 levels were in normal range. Renal and urinary tract ultrasonography revealed multiple nonobstructive stones in the kidneys.

Renal biopsy was performed. Light microscopic examination of the biopsy was normal. Immunofluorescence analysis of the sample revealed no deposition of $\operatorname{IgG}, \operatorname{IgM}$, IgA, Clq, C3, C4 or fibrinogen.

\section{Questions}

1. What is the most likely diagnosis?

2. What is the next step for the management of the patient?

3. What is the prognosis of this condition, and what are the other treatment options for the primary disease?

Authors' contributions All authors read and approved the final manuscript.

\section{Compliance with ethical standards}

Conflict of interest The authors declare that they have no conflicts of interest.

Publisher's note Springer Nature remains neutral with regard to jurisdictional claims in published maps and institutional affiliations.

The answers to these questions can be found at https://doi.org/10.1007/ s00467-019-04440-2.

Nilgun Cakar

nilguncakar@hotmail.com; nilguncakar2@gmail.com

1 Department of Pediatric Nephrology, University of Health Sciences, Ankara Child Health and Diseases Hematology Oncology Training and Research Hospital, Ankara, Turkey

2 Department of Pediatric Nephrology, Ankara University Faculty of Medicine, Ankara, Turkey 